Finally, is the non-proportional Venn diagram really a useful way of illustrating the components of COPD? Often the components of COPD are described as alveolar destruction (emphysema), small airway fibrosis (bronchiolitis) and chronic bronchitis. As most of the airflow obstruction is due to reduced airflow in the small conducting airways, ${ }^{14}$ it seems a little odd not to have small airways disease in the diagram. Should we then start working with an updated Venn diagram? Probably not. Perhaps the problem is that the Venn diagram should never have been taken too literally. It can stimulate thought and illustrate the heterogeneity of COPD; however, the effect of adding numbers to the diagram should motivate us to move on and try to gain new insights into this disease by coming up with novel concepts and potentially new subgroups of COPD which we had no idea ever existed.
Competing interests: None.

Thorax 2008;63:755-756. doi:10.1136/thx.2007.092924

\section{REFERENCES}

1. Snider G. Chronic obstructive pulmonary disease: a definition and implications of structural determinants of airflow obstruction for epidemiology. Am Rev Respir Dis 1989;140(3 Pt 2):S3-8.

2. Soriano JB, Davis KJ, Coleman B, et al. The proportional Venn diagram of obstructive lung disease: two approximations from the United States and the United Kingdom. Chest 2003;124:474-81.

3. Viegi G, Matteelli G, Angino A, et al. The proportional Venn diagram of obstructive lung disease in the Italian general population. Chest 2004;126:1093-101.

4. Marsh SE, Travers J, Weatherall M, et al. Proportional classifications of COPD phenotypes. Thorax 2008;63:761-7.

5. Global Initiative for Chronic Obstructive Lung Disease (GOLD). Global strategy for the diagnosis, management, and prevention of chronic obstructive pulmonary disease. Updated 2007. http://www. goldcopd.com (accessed 5 June 2008)

6. Masoli M, Fabian D, Holt S, et al. The Global Burden of Asthma Report (2004), Global Initiative for Asthma
(G/NA). http://www.ginasthma.com (accessed 5 June 2008)

7. Calverley PMA, Burge PS, Spencer S, et al. Bronchodilator reversibility testing in chronic obstructive pulmonary disease. Thorax 2003;58:659-64.

8. Marsh S, Aldington S, Shirtcliffe P, et al. Smoking and COPD: what really are the risks? Eur Respir J 2006;28:883-4.

9. Lokke A, Lange $P$, Scharling $H$, et al. Developing COPD: a 25 years follow-up study of the general population. Thorax 2006;61:935-9.

10. Buist AS, McBurnie MA, Vollmer WM, et al. International variation in the prevalence of COPD (the BOLD study): a population-based prevalence study. Lancet 2007;370:741-50.

11. Fabbri LM, Romagnoli M, Corbetta $L$, et al. Differences in airway inflammation in patients with fixed airflow obstruction due to asthma or chronic obstructive pulmonary disease. Am J Respir Crit Care Med 2003;167:418-24.

12. Stockley RA. Biomarkers in COPD: time for a deep breath. Thorax 2007:62:657-60.

13. Vestbo J, Anderson W, Coxson HO, et al. Evaluation of COPD Longitudinally to Identify Predictive Surrogate Endpoints (ECLIPSE). Eur Respir J 2008;31:869-73.

14. Hogg JC, Macklem PT, Thurlbeck WM. Site and nature of airway obstruction in chronic obstructive lung disease. N Engl J Med 1968;278:1355-60.

\title{
What evidence could validate the definition of COPD?
}

\section{Roberto de Marco}

Chronic obstructive pulmonary disease (COPD) is one of the leading causes of disability and death in both the developed and developing worlds, ${ }^{1-3}$ and it is largely underdiagnosed. ${ }^{4}$

While it is generally accepted that the ratio between forced expiratory volume in $1 \mathrm{~s}\left(\mathrm{FEV}_{1}\right)$ and forced vital capacity (FVC) or slow vital capacity (SVC) is the most important measure that characterises airflow obstruction, ${ }^{56}$ there is still no consensus on what the best definition of COPD should be.

In an attempt to simplify the diagnosis of COPD, improve the detection of the disease in primary care and standardise methods to measure the prevalence of COPD in different countries, the Global

Correspondence to: Professor R de Marco, Unit of Epidemiology and Medical Statistics, Department of Medicine and Public Health, Strada le Grazie 8, 37134 Verona, Italy; roberto.demarco@univr.it
Initiative for Chronic Obstructive Lung Disease (GOLD) has defined COPD as a post-bronchodilator $\mathrm{FEV}_{1} / \mathrm{FVC}$ ratio $<0.70 .^{5}$

As the $\mathrm{FEV}_{1} / \mathrm{FVC}$ ratio decreases with age, this fixed ratio has been criticised as it may overdiagnose the disease in elderly subjects ${ }^{7}$ and underdiagnose it in young adults. $^{8}$ For this reason, the ATS/ERS guidelines on lung function testing ${ }^{9}$ propose using the lower limit of normality (LLN) instead of a fixed cut-off to define COPD. LLN is the lower fifth percentile of the frequency distribution of the $\mathrm{FEV}_{1} /$ FVC ratio in a healthy population of a given sex and age. The guidelines also point out that the SVC could be more accurate than FVC to diagnose airflow obstruction.

A hot debate between the supporters of the two different points of view is currently ongoing, as can be seen in scientific journals. ${ }^{10}{ }^{11}$ As an epidemiologist I believe there could be sound reasons to support both approaches but, in my opinion, there is insufficient evidence to make one preferable to the other. The positive aspect of the GOLD definition is simplicity and, thanks to this, its use is quite widespread. It relies entirely on the opinions of clinical experts and assumes that an $\mathrm{FEV}_{1} / \mathrm{FVC}$ ratio $<0.70$ is, "on average", a good threshold to discriminate patients with clinically defined COPD from normal subjects. The LLN definition is in theory more rational; it is based on the statistical approach used to derive the reference (or "normal") ranges for biological variables. It depends entirely on the accuracy of "reference equations" (to my knowledge, accurate national reference equations do not currently exist in many cases) and it assumes that (1) everyone outside the range is affected by COPD and (2) all patients affected by COPD are outside the range (in other words, the distribution of diseased and healthy people does not overlap).

The trait that the two approaches have in common is that the definition of the disease is based exclusively on a variablethe $\mathrm{FEV}_{1} / \mathrm{FVC}$ (or $\mathrm{FEV}_{1} / \mathrm{SVC}$ ) - that is distributed along a continuum in the general population. Any definition of COPD based on a dichotomy of this 
frequency distribution is therefore arbitrary. In a certain sense the diagnosis of COPD based only on spirometry results is similar to that of type 2 diabetes using plasma glucose levels or hypertension using blood pressure measurements.

How were the cut-off levels used to discriminate between diseased and healthy people established in medical fields other than pneumology? Usually, cut-off levels are based on studies that compare the distribution of the test variable between patients who have been clinically diagnosed and healthy subjects. Consequently, the choice of threshold is the one that guarantees the best combination of sensitivity and specificity. Diagnostic cut-off points may also be based on longitudinal studies of the risk of adverse outcomes or complications of the disease. ${ }^{12-14}$

Neither the GOLD nor the LLN approach relies on these kinds of studies. The validity of each of the two definitions therefore remains a hypothesis until it has been empirically tested by appropriate large-scale validation studies.

In the current issue of Thorax, Bridevaux et $a l^{15}$ present the results of a longitudinal study that highlights the features of one of the spirometric definitions of COPD (see page 768). The authors analysed the data from the Swiss Study on Air Pollution and Lung Diseases in Adults (SAPALDIA), which is an 11-year follow-up study of a large random sample of adult population (aged 18-60 years at the time of enrolment). ${ }^{16}$ They investigated lung function decline, respiratory care utilisation and healthrelated quality of life in individuals who were classified at baseline as normal individuals or subjects with COPD according to the GOLD classification. Given the size of the cohort, the age range of its members, the quality of the data and the length of the follow-up, the findings presented not only provide information on the prognostic value of the GOLD definition but they go a step further. The authors found that, overall, the subjects with GOLD-defined COPD had poorer longitudinal outcomes than those with normal lung function. If this was true for the subjects with the most severe GOLD-defined COPD (those with $\mathrm{FEV}_{1}<80 \%$ predicted), it was not the case for those with less severe disease (GOLD stage 1 COPD: $\mathrm{FEV}_{1} \geqslant 80 \%$ predicted) who represented more than $85 \%$ of all the patients classified as having COPD by the GOLD criterion. In fact, in the latter group the presence or absence of chronic respiratory symptoms at baseline was the actual predictor of the long-term outcome. Subjects with symptomatic GOLD stage 1 COPD had a faster rate of decline in lung function, increased respiratory care utilisation and a lower health-related quality of life than asymptomatic subjects with normal lung function. On the other hand, subjects with asymptomatic GOLD stage 1 COPD had similar long-term outcomes to those of normal asymptomatic subjects.

Other longitudinal studies have stressed the relevance of respiratory symptoms in the natural history of COPD. ${ }^{17}{ }^{18}$ However, the findings presented by Bridevaux et al suggest that respiratory symptoms should be part of the definition of COPD together with airflow obstruction if the COPD label is to identify subjects with a worse long-term prognosis than those with normal lung function.

Is the lack of predictive power an issue concerning the GOLD but not the LLN definition? There is no answer to this question in the paper by Bridevaux et $a l^{15}$ as the authors did not test the longitudinal performance of the LLN definition. However, given the relationships between the two spirometric criteria, ${ }^{8}$ it is likely that the LLN definition would have performed better in elderly subjects and worse in young subjects than the GOLD definition, with the result that the average predictive power of the two approaches would have been very similar.

In conclusion, the paper by Bridevaux et $a l^{15}$ suggests that definitions of COPD based exclusively on spirometric criteria might have poor prognostic power. Other aspects should be taken into account such as symptoms (or risk factors) in order to increase the validity of the current COPD definitions. Of course, given that the authors did not measure post-bronchodilator lung function and did not test the LLN definition, their findings and suggestions need to be confirmed in future studies.

The debate on the best definition of COPD is likely to last a long time in the absence of "validation studies" such as the one published in this issue of Thorax. Studies on a cross-sectional comparison of the two definitions without any clinical gold standard, or even studies on the distribution of lung function in general population samples, may provide scanty evidence for the choice of a valid diagnostic test for COPD. Perhaps the main lesson we can learn from the paper by
Bridevaux et al is a methodological one: the right answer comes from the right study.

Competing interests: None.

Thorax 2008;63:756-757. doi:10.1136/thx.2008.099895

\section{REFERENCES}

1. Mannino DM, Buist AS. Global burden of COPD: risk factors, prevalence, and future trends. Lancet 2007;370:765-73.

2. Buist AS, McBurnie MA, Vollmer WM, et al (BOLD Collaborative Research Group). International variation in the prevalence of COPD (the BOLD study) a population-based prevalence study. Lancet 2007; 370:741-50.

3. Menezes AM, Perez-Padilla R, Jardim JR, et al (PLATINO Team). Chronic obstructive pulmonary disease in five Latin American cities (the PLATINO study): a prevalence study. Lancet 2005;366:1875-81.

4. Shahab L, Jarvis MJ, Britton J, et al. Prevalence, diagnosis and relation to tobacco dependence of chronic obstructive pulmonary disease in a nationally representative population sample. Thorax 2006;61:1043-7.

5. Global Initiative for Chronic Obstructive Lung Disease (GOLD). Global strategy for the diagnosis, management and prevention of COPD. 2006. www. goldcopd.com.

6. Celli BR, MacNee W (ATS/ERS Task Force). Standards for the diagnosis and treatment of patients with COPD: a summary of the ATS/ERS position paper. Eur Respir J 2004;23:932-46.

7. Schermer TR, Quanjer PH. COPD screening in primary care: who is sick? Prim Care Respir J 2007; 16:49-53

8. Hnizdo E, Glindmeyer HW, Petsonk EL, et al. Case definitions for chronic obstructive pulmonary disease. COPD 2006;3:95-100

9. Pellegrino R, Viegi G, Brusasco V, et al. Interpretative strategies for lung function tests. Eur Respir J 2005;26:948-68.

10. Mannino DM. Defining chronic obstructive pulmonary disease ... and the elephant in the room.Eur Respir J 2007;30:189-90.

11. Pellegrino R, Brusasco V, Viegi G, et al. Definition of COPD: based on evidence or opinion? Eur Respir J 2008;31:681-2.

12. Wareham NJ, Griffin SJ. Should we screen for type 2 diabetes? Evaluation against National Screening Committee Criteria. BMJ 2001;322:986-8.

13. DECODE Study Group. Glucose tolerance and mortality: comparison of WHO and American Diabetic Association diagnostic criteria. Lancet 1999;354:617-21.

14. World Health Organization/International Society of Hypertension Guidelines Subcommittee. Guidelines for the management of hypertension. J Hypertens 1999;17:151-83.

15. Bridevaux P0, Gerbase MW, Probst-Hensch NM, et al. Long-term decline in lung function, utilisation of care and quality of life in modified GOLD stage 1 COPD. Thorax 2008;63:768-74.

16. Ackermann-Liebrich U, Kuna-Dibbert B, ProbstHensch NM, et al (SAPALDIA Team). Follow-up of the Swiss Cohort Study on Air Pollution and Lung Diseases in Adults (SAPALDIA 2) 1991-2003: methods and characterization of participants. Soz Praventivmed 2005;50:245-63.

17. Lindberg A, Jonsson AC, Rönmark E, et al. Ten-year cumulative incidence of COPD and risk factors for incident disease in a symptomatic cohort. Chest 2005; 127:1544-52.

18. de Marco R, Accordini S, Cerveri I, et al. Incidence of chronic obstructive pulmonary disease in a cohort of young adults according to the presence of chronic cough and phlegm. Am J Respir Crit Care Med 2007;175:32-9. 